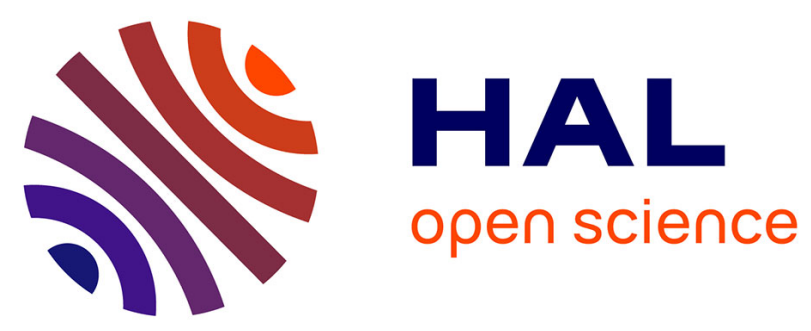

\title{
Illite-smectite mixed-layer minerals in hydrothermal alteration of volcanic rocks: II. One- dimensional HRTEM structure images and formation mechanisms.
}

T. Murakami, Atsuyuki Inoue, Bruno Lanson, A. Meunier, Daniel Beaufort

\section{- To cite this version:}

T. Murakami, Atsuyuki Inoue, Bruno Lanson, A. Meunier, Daniel Beaufort. Illite-smectite mixed-layer minerals in hydrothermal alteration of volcanic rocks: II. One- dimensional HRTEM structure images and formation mechanisms.. Clays and Clay Minerals, 2005, 53, pp.440-451. 10.1346/CCMN.2005.0530502 . hal-00107032

\section{HAL Id: hal-00107032 \\ https://hal.science/hal-00107032}

Submitted on 5 Dec 2007

HAL is a multi-disciplinary open access archive for the deposit and dissemination of scientific research documents, whether they are published or not. The documents may come from teaching and research institutions in France or abroad, or from public or private research centers.
L'archive ouverte pluridisciplinaire HAL, est destinée au dépôt et à la diffusion de documents scientifiques de niveau recherche, publiés ou non, émanant des établissements d'enseignement et de recherche français ou étrangers, des laboratoires publics ou privés. 


\section{ILLITE-SMECTITE MIXED-LAYER MINERALS IN \\ HYDROTHERMAL ALTERATION OF VOLCANIC ROCKS: \\ II. ONE-DIMENSIONAL HRTEM STRUCTURE IMAGES AND \\ FORMATION MECHANISMS}

Takashi Murakami ${ }^{1)}$, Atsuyuki Inoue ${ }^{2)}$, Bruno Lanson ${ }^{3)}$, Alain Meunier ${ }^{4)}$ and Daniel Beaufort ${ }^{4)}$

1) Department of Earth and Planetary Science, The University of Tokyo, Tokyo 113-0033, JAPAN

2) Department of Earth Sciences, Chiba University, Chiba 263-8522, JAPAN

3) LGIT-Maison des GéoScience, BP53, Université de J. Fourier, 38041 Grenoble Cedex 9, FRANCE

4) CNRS UMR6532, Universite de Poitiers, 40, Av. du Recteur Pineau, 86022 Poitiers Cedex, FRANCE

Running Title: 1-D HRTEM structure images of hydrothermal I-S mixed-layer minerals The person to whom correspondence and page proofs should be sent:

Takashi Murakami

Department of Earth and Planetary Science, The University of Tokyo, Tokyo 113-0033, JAPAN

E-mail: murakami@eps.s.u-tokyo.ac.jp 


\section{Abstract}

Smectite illitization was investigated in felsic volcaniclastic rocks from a drill core near the Kakkonda active geothermal system, Japan, using high resolution transmission electron microscopy (HRTEM) that provided one-dimensional structure images of mixed-layer illite-smectite (I-S) minerals normal to [hk0]. Simulated images of a rectorite-like structure revealed that smectite can be distinguished from illite in mixed-layer I-S by HRTEM if the basal spacing of smectite is larger than that of illite. The larger basal spacing of smectite, $1.3 \mathrm{~nm}$ under HRTEM, was obtained by intercalation of dodecylammonium ions into smectitic interlayers. In simulated and observed images normal to $[h k 0]$, tetrahedral $(\mathrm{T})$ and octahedral $(\mathrm{O})$ cation-layers are imaged as dark lines, an illitic interlayer a bright line, and a smectitic interlayer a dark line sandwiched by two bright lines.

Samples are from 435 m (5\% I; R0), 635 m (35\% I; R0), 656 m (62\% I; R1), and $756 \mathrm{~m}(85 \% \mathrm{I}$; R3) depths where \% I is the percent of illite layers in a sample and R is the Reichweite parameter. Sample 435 consisted mostly of smectite, and illite layers occurred, though small in amount, as M1 units (module of type 1, defined as one consisting of two polar T-O-T silicate layers with one central illitic interlayer and two, half smectitic interlayers at the outermost surface; the number corresponds to that of central illitic interlayers). M1 units were dominant and isolated or consecutive smectite layers of $>$ two were present in sample 635. Sample 656 consisted mostly of packets of M1 units of 1 to 5 containing M2 to M5 units occasionally. Isolated or consecutive smectite layers of $>$ two were not present in 656. Illite layers occurred almost as M1 
units in samples 435, 635 and 656, and the number of M1 units increased with increase in \% I. Sample 756 was characterized by the presence of M2 to M10 units accompanied by smectitic interlayers at the external surface and the absence of M1 units and isolated smectite layers. HRTEM data strongly suggest that illitization in a hydrothermal system occurs by precipitation of M1 units for mixed-layer I-S minerals up to $60 \%$ I. This does not require the presence of precursor smectite. Illitization of I-S minerals with more than $60 \%$ I proceeds by precipitation of various types of $M n(n \geq 2)$ units. Illite occurs only as $\mathrm{Mn}(\mathrm{n} \geq 1)$ units throughout illitization.

Key words: Alkylammonium-solvation, HRTEM, hydrothermal system, illite-smectite mixed layer minerals, structure image 


\section{INTRODUCTION}

The transformation of smectite to illite via mixed-layer illite-smectite (I-S) minerals is controlled by physico-chemical environments, and the structures of mixed-layer I-S minerals can give a deep insight into the transformation mechanisms (Altaner and Ylagan, 1997). X-ray diffraction (XRD) and high-resolution transmission electron microscopy (HRTEM) methods have been utilized to determine the structures of mixed-layer I-S minerals (e.g., references in Inoue et al., 2005, this issue for XRD and references below for HRTEM). The former gives information on average layer stacking within crystallites based on Markovian statistics, while the latter gives information on layer stacking in local regions within a crystallite. Thus the two methods are commonly complementary to one another in studies of mixed-layer I-S minerals. The results of one-dimensional XRD structure analysis and characterization of component layers in I-S samples by chemical treatments such as alkylammonium ion and Li-saturation test were described in Inoue et al. (2005), this issue. This HRTEM investigation of one-dimensional structure images of mixed-layer I-S minerals in combination with the previous XRD study (Inoue et al., 2005) provides a better understanding of processes and mechanisms of smectite illitization during hydrothermal alteration of volcanic rocks.

Numerous HRTEM studies of I-S minerals involve one-dimensional lattice imaging (references in Altaner and Ylagan, 1997, and Bauluz et al., 2002 for recent studies). An essential problem in HRTEM investigation of mixed-layer I-S minerals is 
the collapse of expandable interlayers under high vacuum. This makes distinction between smectitic and illitic interlayers, and thus, between smectite and illite in I-S mixed-layers very difficult, if not impossible. Recent improvements in imaging and sample preparation techniques have addressed this problem. Permanent expansion of smectitic interlayers using n-alkylammonium ions for identification of smectitic and illitic interlayers has been accomplished (Bell, 1986; Vali and Köster, 1986; Vali and Hesse, 1990). Ultramicrotomed, transmission electron microscopy (TEM) specimens are usually used for I-S minerals with n-alkylammonium ions. However, ultramicrotomed TEM specimens are thick (about $50 \mathrm{~nm}$ ) and the thickness varies area by area, which changes image contrast significantly. Guthrie and Veblen $(1989,1990)$ have shown that smectitic and illitic interlayers can be distinguished from one another in overfocused images. However, they indicated that ambiguities are still present in the interpretation of such images due to specimen orientation and microscope focus, and that structural information can be obtained near the Scherzer focus. Ion-milled TEM specimens are usually used for observations under overfocus conditions. Stucki and Tessier (1991) have found LR White resin is useful to avoid complete collapse of smectite under high vacuum of TEM. This method has been applied to many HRTEM observations (e.g., Krekeler et al., 2004). It was recommended that LR White resin impregnated, I-S minerals are imaged under overfocus conditions (Kim et al., 1995). To keep expansion of smectitic interlayers under high vacuum of TEM, a freezing technique with liquid nitrogen also has been proposed (Murakami et al., 1993). Dong et al. (1997) concluded through their HRTEM observations that smectite 
illitization proceeds: (1) pure smectite, (2) smectite with small proportions of discrete R1 I-S and illite, (3) R1 I-S with small proportions of smectite and illite, (4) illite with some smectite and R1 I-S, and (5) illite where R denotes the Reichweite parameter. Subsequent observations have supported this conclusion (Tillick et al., 2001; Yan et al., 2001; Bauluz et al., 2002). However, because these authors employed one-dimensional lattice imaging under overfocus conditions, the obtained contrast does not necessarily correspond to the projected potential of mixed-layer I-S minerals, which leads to some ambiguities in the interpretation of TEM images (Guthrie and Veblen 1990). In the present study, I-S minerals formed by hydrothermal alteration were intercalated with $\mathrm{C}_{12}$-alkylammonium ions to ensure expansion of smectitic interlayers under high vacuum of TEM. Then, we examined the structural information by HRTEM imaging each tetrahedral $(\mathrm{T})$ and octahedral $(\mathrm{O})$ tetrahedral $(\mathrm{T})$ cation-layer in the T-O-T silicate layers, which distinguishes smectite from illite in the mixed-layer I-S minerals. For the structural information we employed one-dimensional structure imaging instead of conventional, one-dimensional lattice imaging.

\section{EXPERIMENTAL}

\section{Samples}

Samples used for the present TEM study were a smectite-to-illite series in felsic volcaniclastic rocks from a drill core (IT-2) near the Kakkonda active geothermal system, Japan (Inoue et al., 2004). Clay fractions $(<2 \mu \mathrm{m})$ were obtained by separating 
them from rock samples using ultrasonic vibration and centrifugation, and used for the present TEM study. The samples were from 435 m (5\% I; Reichweite R0), $635 \mathrm{~m}$ (35\% I; R0), 656 m (62\% I; R1), and 756 m (85\% I; R3) depths. The depths are hereafter used for sample names. The percent of illite layers (\% I) data in parentheses are from Inoue et al. (2005) except for that of sample 656 which are from Inoue et al. (2004). The I-S samples were intercalated with $\mathrm{C}_{12}$-alkylammonium (dodecylammonium) ions to permanently expand smectitic interlayers under high vacuum of TEM. Sample 435 was also intercalated with $\mathrm{C}_{18}$-alkylammonium (octadecylammonium) ions to compare expandability to that with $\mathrm{C}_{12}$-alkylammonium ions. Rectorite ( $\mathrm{RAr}-1$, Arkansas) of Clay Mineral Society standard was also used without intercalation to compare the electron diffraction pattern to those of the I-S minerals.

\section{Transmission electron microscopy}

A JEOL JEM 2010 microscope was used for the HRTEM observation. The TEM had a point to point resolution of $0.2 \mathrm{~nm}$ with a spherical aberration coefficient of 0.5 $\mathrm{mm}$ and was operated at $200 \mathrm{kV}$. The TEM specimens were prepared by impregnating the I-S crystals in resin, pushing them between two glass slides, and slicing and polishing them mechanically. This procedure made it easy to obtain TEM images normal to $[h k 0]$. The polished mixed-layer crystals were sandwiched by two Mo TEM grids with adhesive, and thinned to electron transparency by Ar ion milling (Dual Ion Mill, Gatan Ltd.) with the grids on a cold stage cooled by liquid nitrogen. The TEM specimens were thinned at $4 \mathrm{kV}$ of operation voltage, $30 \mu \mathrm{A}$ of specimen current and 
$20^{\circ}$ of specimen tilt angle. HRTEM images were observed near the Scherzer focus (-42 $\mathrm{nm})$, and taken at $\mathrm{x} 120,000$ or $\mathrm{x} 150,000$ of magnification because higher magnification caused significant damage on the crystals. Some of the HRTEM negatives were digitized and processed to remove noise and the image of amorphous material by rotational filtering (Kilaas 1998) implemented within Digital Micrograph V. 2.5, Gatan Ltd. The use of rotationally filtered (RF) images has been described in detail by Banfield and Murakami (1998). Selected area electron diffraction (SAED) was employed to measure $d$ values of mixed-layer I-S minerals. The d values were originally calibrated by using metal Au single crystals, recalibrated by fringes of mineral species with known d values, such as biotite and chlorite, and directly measured on images. The errors of the $d$ values were estimated to be $\pm 0.05 \mathrm{~nm}$.

HRTEM imaging alone cannot directly distinguish a T-O-T silicate layer of illite from that of smectite. We first assumed a polar model (e.g., Altaner and Ylagan, 1997) to describe the 2:1 layers of mixed-layer I-S minerals: one illitic interlayer is sandwiched by a pair of tetrahedral sheets and a pair of half octahedral sheets of illite, and one smectitic interlayer by those of smectite. The former is hereafter referred to as an illitic layer of mixed-layer I-S minerals, and the latter a smectitic layer (Figure 1). An M1, module of type 1, unit is defined as consisting of two polar T-O-T silicate layers with a central illitic interlayer and two, half smectitic interlayers at the outermost surface, which is denoted as -SIS- in Inoue et al. (2005), this issue. In a sequence of -SISISIS-, for instance, I and S denote the illitic and smectitic interlayers respectively, and $-\mathrm{S}$ and $\mathrm{S}$ - represent a half part of expandable interlayer at the outermost surface. An 
M2 unit, denoted as -SIIS-, consists of three T-O-T silicate layers and three interlayers: one homogeneous, non-polar T-O-T silicate layer of illite is located at the center sandwiched by two polar T-O-T silicate layers and two illitic interlayers are in the middle and two, half smectitic interlayers at the outermost surface. Thus, an increase in $\mathrm{n}$ of an Mn unit increases the number of non-polar T-O-T silicate layers of illite. Similar classification was applied to the interpretation of TEM images of I-S minerals by Bauluz et al. (2000).

\section{Simulation}

Simulated images calculated using MacTempas software (Total Resolution Co.) were compared to observed HRTEM images to provide information on the mixed-layer I-S structures. The crystal structure of $1 \mathrm{M}$ illite for the simulation was based on $1 \mathrm{M}$ muscovite by Guthrie and Veblen (1989) who transformed the coordinates of $2 \mathrm{M}_{1}$ muscovite (Richardson and Richardson, 1982) to those of 1M. Simulations were made for a rectorite-like, perfectly ordered I-S (hereafter, rectorite-like I-S) derived from 1M illite because the crystal structures of mixed-layer I-S minerals consist of illitic and smectitic interlayers and T-O-T silicate layers (e.g., Guthrie and Veblen, 1989). We assumed a polar structure with a periodic repetition of an illitic and smectitic interlayer between T-O-T silicate layers, and chemical formulas of $\mathrm{K}_{0.8} \mathrm{Al}\left(\mathrm{Si}_{3.2} \mathrm{Al}_{0.8}\right) \mathrm{O}_{10}(\mathrm{OH})_{2}$ and $\mathrm{Na}_{0.3} \mathrm{Al}\left(\mathrm{Si}_{3.7} \mathrm{Al}_{0.3}\right) \mathrm{O}_{10}(\mathrm{OH})_{2}$ for illitic and smectitic layers, respectively. Hydrogen atoms were ignored for the calculations. Because mixed-layer I-S minerals should be imaged with an electron beam normal to the $\mathrm{c}^{*}$-axis or along [hk0] to distinguish illitic from 
smectitic interlayers (e.g., Guthrie and Veblen 1989), the simulations were made along [530]. The simulated images of rectorite-like I-S with $\mathrm{d}_{001}=2.3 \mathrm{~nm}$ were examined because the SAED patterns of sample $435(5 \% \mathrm{I})$ had $\mathrm{d}_{001}=1.3 \mathrm{~nm}$ as mentioned below, i.e., smectite with $\mathrm{C}_{12}$-alkylammonium ions collapsed incompletely to show a $1.3 \mathrm{~nm}$ basal-spacing under high vacuum of TEM. The basal-spacing of the illitic layer of rectorite-like I-S was assumed to be $1.0 \mathrm{~nm}$ in all simulations. The objective aperture radius was $3.5 \mathrm{~nm}^{-1}$. Calculations were made changing a defocus amount from -82 to $-22 \mathrm{~nm}$ with an increment of $20 \mathrm{~nm}$ and changing a specimen thickness from 2 to $10 \mathrm{~nm}$ with an increment of $2 \mathrm{~nm}$.

To examine the effects of other factors (e.g., cation occupancies) on HRTEM contrast, we made further calculations at a defocus $-42 \mathrm{~nm}$ (the Scherzer focus) and a specimen thickness of $4 \mathrm{~nm}$ where we obtained a contrast that corresponds to the real structure (Figure 1). The further calculations were made for the following conditions: (1) The $\mathrm{d}_{001}$ values of the rectorite-like I-S were 2.0, 3.0 and $6.0 \mathrm{~nm}$, assuming that the basal-spacings of a smectitic layer of the rectorite-like I-S were 1.0, 2.0 and $5.0 \mathrm{~nm}$, respectively. (2) The interlayer occupancies of $\mathrm{K}$ and $\mathrm{Na}$ were $0.0,0.25,0.5,0.75$, and 1.0 for the illitic and smectitic interlayers, respectively. (3) The octahedral sites were occupied by $0.5 \mathrm{Al}$ and $0.5 \mathrm{Fe}$. (4) The rectorite-like I-S had a non-polar structure. (5) An electron beam was along [ $h k 0]$ where $1 \leq h \leq 7$ and $1 \leq k \leq 5$. [100]/[110]/[1-10] and $[010] /[310] /[3-10]$ images were not calculated because they are two-dimensional structure images (e.g., Kogure and Banfield, 2000). 


\section{RESULTS}

\section{Simulated TEM images}

A simulated image of rectorite-like I-S with $\mathrm{d}_{001}=2.3 \mathrm{~nm}$ normal to [530] is compared to the crystal structure in Figure 1. Each of the tetrahedral and octahedral cation-layers corresponded to one dark line, and the dark line of the tetrahedral cation-layer was slightly darker than that of the octahedral cation-layer. Thus, each T-O-T silicate layer resulted in one set of three dark lines in the simulated image. The illitic interlayer made one bright line and the smectitic interlayer one dark line sandwiched by bright lines. The simulated image indicates that we can distinguish illitic interlayers from smectitic ones in any mixed-layer I-S minerals when smectite does not collapse completely. Simulated images similar to that in Figure 1 were obtained when a specimen thickness was $<10 \mathrm{~nm}$ at a defocus $-42 \mathrm{~nm}$, and when it was $<4 \mathrm{~nm}$ at a defocus $-22 \mathrm{~nm}$. However, simulated images did not correspond to the projected potential of the T-O-T silicate layers when defocus amounts were $<-62 \mathrm{~nm}$ or $>-2 \mathrm{~nm}$.

Our simulated, structure image is essentially different from lattice images of which contrast does not necessarily correspond to the projected potential of mixed-layer I-S minerals (e.g., Guthrie and Veblen, 1989). In their calculations, Guthrie and Veblen (1989) showed that one T-O-T silicate layer is imaged as a pair of dark fringes at the Scherzer focus and with a specimen thickness of $5.2 \mathrm{~nm}$. They suggested that the sequence of illite and smectite is determined practically under overfocus conditions where heavy dark fringes are present near the position of the smectitic interlayers and 
weaker dark fringes near the illitic interlayers. However, the layer thickness varies with factors such as defocus and specimen tilt if it is measured from images (Guthrie and Veblen, 1989). In contrast, we can measure the layer thickness that is a distance from one $\mathrm{O}$ cation layer to an adjacent one directly from an HRTEM image in the present simulation as we demonstrate with 1.0 and $1.3 \mathrm{~nm}$ in Figure 1.

The variation of simulated images with a function of the basal-spacing of the smectitic layer of rectorite-like I-S is shown in Figure 2. Bright lines appear at the smectitic interlayers for the basal-spacing of $1.0 \mathrm{~nm}$ (Figure 2a). If smectite collapses completely to a 1.0-nm basal-spacing, the illitic interlayers cannot be distinguished from the smectitic interlayers in mixed-layer I-S minerals. The dark lines or fringes at the smectitic interlayers were increased in number with increasing the basal-spacing of the smectitic layer (short, vertical bars in Figure 2). Figures $2 \mathrm{c}$ and $2 \mathrm{~d}$ suggest that mere superimposition of a few rectorite-like I-S layers generates some additional dark fringes in the smectitic interlayers. In any mixed-layer I-S minerals with expanded interlayers, bright lines adjacent the dark lines of the tetrahedral cation-layers appear at the smectitic interlayers (e.g., arrows in Figure 2).

The dark and bright fringes at the smectitic interlayers occur due to the effect of truncation of a Fourier series, essentially a result of the diameter of the objective aperture (e.g., Buseck, 1992). Although the dark fringes at the smectitic interlayers appear due to the truncation of a Fourier series, the basal-spacings of the smectitic layers (1.0, 1.3, 2.0 and 5.0 in Figures 2a, b, c and d, respectively) are real. The occupancies in the range of 0.0 to 1.0 of $\mathrm{K}$ and $\mathrm{Na}$ at the interlayers did 
not affect the contrast at both the illitic and smectitic interlayers. This indicates that one-dimensional structure imaging cannot distinguish vermiculite from smectite.

Although the content of vermiculite in the present samples is small, $5 \%$ at maximum by ethylene glycol solvation, vermiculite does not significantly affect the smectite illitization at Kakkonda (Inoue et al., 2005). Therefore we simply assumed that all of the 1.3-nm layers are smectitic. We did not calculate the images of rectorite-like I-S with $\mathrm{C}_{12}$-alkylammonium ions in the smectitic interlayers because the collapsed structure is not known. We infer little effects of $\mathrm{C}_{12}$-alkylammonium ions that contain only light elements on the HRTEM contrast because there are no effects of the interlayer occupancies on the HRTEM contrast as mentioned above.

A simulated image assuming $0.5 \mathrm{Al}$ and $0.5 \mathrm{Fe}$ at the octahedral sites was the same as that in Figure 1 except that the contrast at the octahedral cation layer was slightly thicker and darker than that in Figure 1. There was no difference in contrast between the polar and non-polar models. [ $h k 0$ ] simulated images varying $1 \leq h \leq 7$ and $1 \leq k \leq 5$ were the same as that in Figure 1. This occurs because rectorite-like I-S is a sheet silicate. $[100] /[110] /[1-10]$ and $[010] /[310] /[3-10]$ images were not calculated as mentioned above.

\section{Selected area electron diffraction patterns}

Figure 3 gives typical SAED patterns of the present samples as well as Arkansas rectorite. Smectitic interlayers of Arkansas rectorite without $\mathrm{C}_{12}$-alkylammonium ions collapsed almost completely to give a $\mathrm{d}_{002}$ value of $1.00 \mathrm{~nm}$ (Figure 3a). Smectite 
intercalated with $\mathrm{C}_{12}$-alkylammonium ions (sample 435) collapsed incompletely and gave a $\mathrm{d}_{001}$ value of $1.28 \mathrm{~nm}$ (arrow in Figure $3 \mathrm{~b}$ ) compared to that of $1.71 \mathrm{~nm}$ by XRD under air (Inoue et al., 2005), which suggests that an M1 unit has $\mathrm{d}_{001}$ and $\mathrm{d}_{002}$ values of 2.28 and $1.14 \mathrm{~nm}$, respectively, under high vacuum of TEM. Smectite intercalated with $\mathrm{C}_{18}$-alkylammonium ions had a $\mathrm{d}_{001}$ value of $1.35 \mathrm{~nm}$ (arrow in Figure $3 \mathrm{c}$ ) that was near that of smectite intercalated with $\mathrm{C}_{12}$-alkylammonium ions within error. We therefore only used $\mathrm{C}_{12}$-alkylammonium ions for further HRTEM study. Mixed-layer I-S minerals of samples 635 and 656 had a same d value of $1.14 \mathrm{~nm}$ (arrows in Figures 3d and e, respectively), suggesting that $\mathrm{M} 1$ units of a $\mathrm{d}_{001}$ value of $2.28 \mathrm{~nm}$ are dominant in those samples. The d value of $1.00 \mathrm{~nm}$ indicates that sample 756 has packets of illite (arrow in Figure 3f). In sample 756, less ordered I-S minerals than illite such as M3 units were also present as shown by the diffraction spots and diffuse toward the center from the arrow head in Figure 3f.

\section{Observed TEM images}

Sample 435. Mixed-layer I-S of sample 435 consisted mostly of smectite packets with a few to ten T-O-T silicate layers (Figure 4a). A thick packet may be composed of a few sub-packets. The basal spacings of the smectitic layers were $1.3 \mathrm{~nm}$ (S's in Figures $4 \mathrm{~b}$ and c), which is consistent with the result of the SAED pattern (Figure 3b). Figures $4 b$ and $\mathrm{c}$ indicate that illitic interlayers are distinguished from smectitic interlayers as was predicted by the above simulation (Figure 1): an illitic interlayer corresponds to one bright line between two, adjacent T-O-T silicate layers (indicated by a bracket in Figure 
4) and a smectitic interlayer corresponds to one dark line and two bright lines sandwiched by two, adjacent T-O-T silicate layers. Figures $4 \mathrm{~b}$ and $\mathrm{c}$ also indicate that the smectitic layers were homogeneously intercalated with $\mathrm{C}_{12}$-alkylammonium ions in general. Although smectitic layers were predominant in sample 435, illitic layers occurred as M1 (-SIS-) units as shown in Figures $4 \mathrm{~b}$ and c. Figures $4 \mathrm{~b}$ and c display two M1 units and one M1 unit, respectively, both on smectitic layers. A stack of M1 units of more than three was not observed. We found only one example of two consecutive non-polar illitic layers within smectite packets.

Sample 635. Sample 635 consisted of packets with a few to ten T-O-T silicate layers (Figure 5a) and the packets were up to several micrometers long. M1 (-SIS-) units were dominant (Figure 5b), which is consistent with the $d$ value of $1.14 \mathrm{~nm}$ (Figure 3d). Smectite layers were observed as being both isolated from and attached to M1 units (Figure 5c). The XRD examination indicated that sample 635 contains M1 units with dominant smectite layers using a $\mathrm{C}_{12}$-alkylammonium saturated specimen and is described as a structure of Reichweite $=0$ (e.g., the occurrence probabilities of layer-doublets and layer-triplets ; $\mathrm{W}_{\mathrm{SS}}=0.42, \mathrm{~W}_{\mathrm{IS}}=0.23, \mathrm{~W}_{\mathrm{SSS}}=0.27, \mathrm{~W}_{\mathrm{SIS}}=0.15$ ) using Ca-, ethylene glycol-saturated specimens (Inoue et al., 2005). The apparent discrepancy in frequency of M1 units may be due to the thickness of packets observed between HRTEM and XRD (Drits, 1987). The thinner the packets observed in TEM, the more the heterogeneity in layer sequence is facilitated so that M1 units become visible in thinner packets. M2 (-SIIS-) or M3 (-SIIIS-) units were rarely observed (Figure 5c). 
There are two dark fringes (indicated by two pairs of two facing arrows in Figure 5b) between two M1 units in the bottom of Figure 5b. The two M1 units are clearly separated in the left of Figure 5b. However, they are attached to one another through a smectitic layer of a d value of $1.7 \mathrm{~nm}$ in the center and right. It is not known whether the two individual M1 units coalesce into one crystal (i.e., a sequence of -SISIS-) in the center and right or they are attached to one another only physically. An arrow in Figure 5c shows a 1.5-nm smectitic layer although the other part of the same layer has a 1.3-nm smectitic layer. This may show heterogeneous collapse of a smectitic interlayer, or show the presence of vermiculite, although the occurrence of vermiculite layers was rare as suggested by Inoue et al. (2005).

Sample 656. Sample 656 consisted of packets with a few to ten T-O-T silicate layers (Figure 6a). M1 units were predominant; the observed packets were a stack of M1 units of 1 to 5 . Figure $6 \mathrm{~b}$ shows a perfectly ordered stack of five M1-units though partly damaged. In addition, M2- to M5 units occurred occasionally, but isolated smectite layers or packets were not observed.

Figure 7 shows isolated and stacked M1 units together with isolated M2 units. The M2 unit in the right-top of Figure 7 changes to an M1 unit in the middle losing the T-O-T silicate layer at the top of the M2 unit at the arrow with a, which suggests growth of the T-O-T silicate layer for the formation of the M2 unit. The M1 unit separated from the original M2 unit extends and merges with another M1 unit that is separated from a packet of three M1 units (arrow with b). The two M1 units may form one packet 
through a 1.5-nm smectite layer at the arrow c in Figure 7, or it is possible that the two M1 units are attached to one another only physically. If the former is correct, the outermost surface of the middle T-O-T silicate layer of the M2 unit changes its nature from illitic to smectitic somewhere between the arrows a and c. The separation of one of the three M1 units in the top (arrow with $b$ in Figure 7) indicates that a packet of M1 units can be separated at the smectitic interlayer as is also suggested in a pair of fringes shown by the arrows in Figure $5 b$.

The packet of the three M1 units in the top of Figure 7 releases one M1 unit at the arrow with $b$; a smectitic interlayer between the remaining packet of two M1 units (arrow with S) is changed to an illitic interlayer (arrow with I) in the middle of the packet. The change of the smectitic to illitic interlayer results in formation of one M3 unit from two, stacked M1 units. This kind of microstructure was, however, rarely observed.

There found six T-O-T silicate layers in the middle and two isolated M1 units at the top and bottom in Figure 8. The six T-O-T silicate layers consist of two M2 units in the far right while they are composed of one M1 unit, one isolated smectite layer and one M2 unit in the left. This results from a change of the nature of an interlayer from illitic (arrow with I in Figure 8) to smectitic (arrow with $\mathrm{S}$ in Figure 8). A closer look of this interlayer reveals that the interlayer is smectitic in the range indicated by a and $\mathrm{c}$ in Figure 8 , and illitic in the range indicated by $b$ and $d$. The change of the nature of the interlayer can also occur by heterogeneous collapse of a smectitic interlayer. The microstructures described in this paragraph were rarely observed in sample 656. 
Sample 756. Sample 756 consisted of packets with a few to ten T-O-T silicate layers (Figure 9). M2 to M10 units were present in sample 756, which is consistent with the presence of the diffuse spot near the arrow in Figure 3f. Although M3 units (arrows in Figure 9) were most abundant in number, the abundance of M3 units in sample 756 was less than one-third. The inset of Figure 9 demonstrates a typical example of an M3 unit; between the four T-O-T silicate layers there exist three illitic interlayers, which is compared to the simulated image in Figure 1. Isolated smectite layers were not found in 756 by HRTEM investigation although XRD indicates it contained $12.5 \%$ smectite layers (Inoue et al., 2005). These suggest that $M n(n \geq 2)$ units are smectitic at the external surface as is an M1 unit mentioned above.

Figure 10 shows changes in smectitic and illitic nature at the boundaries of packets 1,2 and 3. In area $\mathrm{b}$ (arrow with $\mathrm{b}$ Figure 10a) the boundary between packets 1 and 2 is smectitic, and that between packets 2 and 3 is illitic (arrows with S and I in Figure 10b, respectively). In area c (arrow with c Figure 10a) the boundary between packets 2 and 3 is changed to smectitic while that between packets 1 and 2 stays smectitic (arrows with S in Figure 10c). In area d (arrow with d Figure 10a) the boundary between packets 1 and 2 becomes illitic (arrow with I in Figure 10d). Figure 10 indicates that the outermost interlayers of Mn units can change their nature from smectitic to illitic.

\section{DISCUSSION}


The T-O-T silicate layers were imaged as sets of three dark lines for both illite and smectite for the present HRTEM study. If smectitic interlayers collapse completely, the one-dimensional structure images do not provide any information on the sequence of mixed-layer I-S minerals (Figure 2a). However, the expansion of smectitic interlayers was maintained under high vacuum of TEM by the intercalation of $\mathrm{C}_{12}$-alkylammonium ions. No apparent indication of $\mathrm{C}_{12}$-alkylammonium expulsion was observed with a few, possible exceptions (e.g., Figure 8). Consequently, the one-dimensional structure imaging and the expansion of smectitic interlayers led to unambiguous identification of illitic and smectitic interlayers, which can elucidate the structures of I-S minerals, and provide detailed insight into the processes and mechanisms of smectite illitization with more accuracy than previously reported using lattice fringe images (Dong et al., 1997; Bauluz et al., 2002, and references therein).

HRTEM investigation indicates that sample 435 is composed mostly of smectite and is consistent with XRD results by Inoue et al. (2005). Illitic layers occur, though small in amount, as M1 units (Figures 4b and 4c). Packets of M1 units of 1 to 5 are predominant in samples 635 (35\% I) and 656 (60\% I) (Figures 5a and 6b, respectively). These indicate that the increase in illite content in the Kakkonda I-S minerals with up to $60 \%$ I results from the formation of M1 units but not from discrete illite layers independent of M1 units. The difference in illite content between samples 635 (35\% I) and $656(60 \% \mathrm{I})$ is due to the difference in abundance of isolated smectite and $\operatorname{Mn}(1 \leq n \leq 5)$ units in the two samples. The observations strongly suggest that illitization 
in the range of smectite to I-S with $60 \%$ I occurs by precipitation of M1 units. This mechanism does not require the presence of precursor smectite. The observations also suggest that M1 units are somewhat stable by their distinct occurrence in samples with up to $60 \%$ I. The uniqueness and stability of M1 units have been discussed for long time (Dong et al., 1997 and references therein) based on the data of rectorite-like I-S. Dong et al. (1997) concluded that M1 I-S mineral is unique based on the chemical composition and common layer spacing, which is recently confirmed by a first-principles study (Stixrude and Peacor, 2002). Our HRTEM observations further confirm the uniqueness and stability of M1 units.

There can be a few mechanisms for illitization of I-S minerals of more than $60 \%$ I or formation of $M n(n \geq 2)$ units: they are $M n+S=M(n+1)$, two M1s $=M 3$, and $M n+M m=M(n+m+1)$ by apparent layer-by-layer formation, and direct precipitation of $\operatorname{Mn}(n \geq 2)$. Fundamental constraints of the mechanisms are based on HRTEM observations of samples 635,656 and 756: predominant M1 units with few $M n(n \geq 2)$ units in sample 635, predominant M1 units with some $M n(2 \leq n \leq 5)$ units and without isolated smectite in sample 656 , and $\operatorname{Mn}(2 \leq n \leq 10)$ units without M1 units or isolated smectite in sample 756. The progressive formation of illitic interlayers in a smectite packet is not consistent with the above HRTEM observations, and thus, mere layer-by-layer formation is excluded from the main mechanism of illitization.

In theory, one Mn unit with one homogeneous smectite layer within a packet can make one $M(n+1)$ unit by apparent layer-by-layer formation at the outermost interface, as suggested by an example of the formation of one M2 unit in Figure 8. 
However, there are few isolated smectite layers in 656. Therefore, the mechanism of $M(n+1)$ unit formation from a combination of Mn units and smectite should be excluded from the main mechanism of illitization.

A pair of M1 units can be transformed to one M3 unit by replacement of a smectitic interlayer by an illitic interlayer. Our HRTEM observations are: there a few possible examples suggesting this transformation in sample 656 (e.g., arrows with I and $\mathrm{S}$ in Figure 7), the abundance of M3 units in sample 756 is less than one-third, and M2 units already grow in sample 656 (Figures 7 and 8). In addition, a stack of M1 units can make only Mn(odd) units whereas various Mn(even) units are also present in sample 756. Therefore, layer-by-layer formation of $\mathrm{Mn}(\mathrm{n} \geq 3)$ units using precursor M1 units could be a possible mechanism for illitization, but HRTEM data suggest this is not a major contributor.

Because the diameter of the I-S particles is up to several $\mu \mathrm{m}$ and the thickness is usually less than $10 \mathrm{~nm}$, it is almost impossible to observe a whole packet of I-S by HRTEM. However, Figure 7 clearly indicates the formation of an M2 unit. If this formation is interpreted as a growth of a T-O-T silicate layer on the M1 unit, we should have observed a growth of a T-O-T silicate layer on a stack of M1 units that are dominant in sample 656 (for instance, a sequence of -SIISISISIS-). Because we do not observe such overgrowth, the formation of the M2 unit in Figure 7 should be interpreted as formation of M2 units themselves by precipitation and growth (e.g., Inoue et al., 1988). A growth mechanism does not require the presence of precursor M1 units but rather requires direct precipitation from solution. The precipitation and growth 
mechanism can also make any $\operatorname{Mn}(n \geq 2)$ units and is consistent with the occurrence of $\operatorname{Mn}(n \geq 2)$ units in sample 756. Thus, direct precipitation of $M n(n \geq 2)$ units is a possible, main mechanism for illitization of mixed-layer I-S minerals of more than $60 \% \mathrm{I}$.

For illitization at the final stage, e.g., formation of $M n(n \geq 10)$ units, it is possible that one Mn unit stacked by one Mm unit forms one $M(n+m+1)$ unit by layer-by-layer replacement at the boundary. Figure 10 demonstrates such examples. The external surface of an Mn unit must be smectitic to explain the illite contents of the samples revealed by X-ray diffraction analysis (Inoue et al, 2005). The external surfaces of packets 1, 2 and 3 in Figure 10a should be smectitic originally as shown in Figure 10c. The smectitic nature changes to illitic as shown in Figures $10 \mathrm{~b}$ and 10d, which results in an increase in $\mathrm{n}$ of Mn units.

The present HRTEM observations of mixed-layer I-S minerals in a hydrothermal system clearly show that illitization occurs by precipitation of M1 units for mixed-layer I-S minerals with up to $60 \% \mathrm{I}$. This conclusion is consistent with the XRD data indicating that the precipitation of I-S with Reichweite $(\mathrm{R})=0$ (e.g., sample 635) and R1 (e.g., sample 656) structures occurs in a narrow temperature range from 154 to $158^{\circ} \mathrm{C}$ and an intermediate product of the two structures is a physical mixture of R0 and R1 phases (e.g., sample 645) in Kakkonda (Inoue et al., 2005). With increasing temperature, the illitization takes place apparently continuously via various types of orderings in I-S structures. The illitization of I-S structures with more than $60 \%$ I proceeds by precipitation of various types of $M n(n \geq 2)$ units and further illitization can occur by the formation of an illitic interlayer at the external interface of two Mn units at 
temperatures between $160-200{ }^{\circ} \mathrm{C}$. The predominant mechanism of precipitation over layer-by-layer transformation was previously proposed (e.g., Dong et al., 1997), and the present structure images provide distinct confirmation of the precipitation mechanism. The present study indicates that the precipitation of M1 units for I-S with $<60 \%$ I and that of $\mathrm{Mn}(\mathrm{n} \geq 2)$ units with $>60 \%$ I are the main illitization mechanisms and illite occurs only as $M n(n \geq 1)$ units throughout illitization, which is different from previously reported.

\section{CONCLUSIONS}

The observations of one-dimensional HRTEM structure images of mixed-layer

I-S in a hydrothermal system give us conclusions below:

1. By one-dimensional HRTEM structure imaging, we can distinguish one tetrahedral or octahedral sheet from the others in a T-O-T silicate layer, and therefore, an illitic layer from a smectitic layer if smectite does not collapse completely.

2. Mixed-layer I-S consists of stacks of sub-units of $M n(n \geq 0)$. Here, for example, an $M 1$ unit is defined as one consisting of two polar T-O-T silicate layers with one central illitic interlayer and two, half smectitic interlayers at the outermost surface; an increase in $\mathrm{n}$ of an $\mathrm{Mn}$ unit increases the number of non-polar T-O-T silicate layers of illite at the center.

3. Smectite illitization occurs in a manner that M1 units increase in number in M0 units for mixed-layer I-S with up to $60 \% \mathrm{I}$, and then, $\mathrm{Mn}(\mathrm{n} \geq 2)$ units increase in M1 
units for I-S with $>60 \%$ I. The increases in M1 and $\mathrm{Mn}(\mathrm{n} \geq 2)$ units correspond to narrow temperature ranges, $154-158$ and $160-200{ }^{\circ} \mathrm{C}$, respectively, in Kakkonda. Illite occurs only as $\mathrm{Mn}(\mathrm{n} \geq 1)$ units throughout illitization.

4. The dominant mechanism of illitization is precipitation of various types of $M n(n \geq 1)$ units from solution, and this mechanism does not require the presence of precursor smectite or M1 units. The consecutive change of the R parameter from R0 to R3 revealed by XRD (Inoue et al., 2005) is well explained by the precipitation of M1 units followed by $\mathrm{Mn}(\mathrm{n} \geq 2)$ units.

\section{ACKNOWLEDGMENTS}

The authors are grateful to T. Tachikawa and T. Takeshige for the technical assistance. This manuscript was greatly improved by the comments of $\mathrm{H}$. Dong, $\mathrm{M}$. Krekeler, D. McCarty and one anonymous reviewer. The electron microscopy was performed in the Electron Microbeam Analysis Facility for Mineralogy at the Department of Earth and Planetary Science, the University of Tokyo. This work was supported by the Science Grant of the Ministry of Education, Science and Culture. 


\section{REFERENCES}

Altaner, S.P. and Ylagan, R. F. (1997) Comparison of structural models of mixed-layer illite/smectite and reaction mechanisms of smectite illitization. Clays and Clay Minerals, 45, 517-533.

Banfield, J.F. and Murakami, T. (1998) Atomic-resolution transmission electron microscope evidence for the mechanism by which chlorite weathers to $1: 1$ semi-regular chlorite-vermiculite. American Mineralogist, 83, 348-357.

Bauluz, B., Peacor, D R. and Gonzalez Lopez, J.M. (2000) Transmission electron microscopy study of illitization in pelites from the Iberian Range, Spain: layer-by-layer replacement? Clays and Clay Minerals, 48, 374-384.

Bauluz, B., Peacor, D.R. and Ylagan, R.F. (2002) Transmission electron microscopy study of smectite illitization during hydrothermal alteration of a rhyolitic hyaloclastite from Ponza, Italy. Clays and Clay Minerals, 50, 157-173.

Bell, T.E. (1986) Microstructure in mixed-layer illite/smectite and its relationship to the reaction of smectite to illite. Clays and Clay Minerals, 34, 146-154.

Buseck, P.R. (1992) Imaging and diffraction, In Mineralogical Society of America Reviews in Mineralogy, 27, 1-36.

Dong, H., Peacor, D.R. and Freed R.L. (1997) Phase relations among smectite, R1 illite-smectite, and illite. American Mineralogist, 82, 379-391.

Drits, V. A. (1987) Mixed-layer minerals: diffraction methods and structural features. Proceedings of International Clay Conference, Denver, 33-45. 
Guthrie, G.D., Jr. and Veblen, D.R. (1989) High-resolution transmission electron microscopy of mixed-layer illite/smectite: Computer simulations. Clays and Clay Minerals, 37, 1-11.

Guthrie, G.D., Jr. and Veblen, D.R. (1990) Interpreting one-dimensional high-resolution transmission electron micrographs of sheet silicates by computer simulation. American Mineralogist, 75, 276-288.

Inoue, A., Velde, B., Meunier, A. and Touchard, G. (1988) Mechanism of illite formation during smectite-to-illite conversion in a hydrothermal system. American Mineralogist, 73, 1325-1334.

Inoue, A., Meunier, A. and Beaufort, D. (2004) Illite-smectite mixed-layer minerals in felsic volcaniclastic rocks from drill cores, Kakkonda, Japan. Clays and Clay Minerals, 52, 66-84.

Inoue, A., Lanson, B., Fernandes, M. M., Sakharov, B. A., Murakami, T., Meunier, A. and Beaufort, D. (2005) Illite-smectite mixed-layer minerals in hydrothermal alteration of volcanic rocks: I. One-dimensional XRD structure analysis and characterization of component layers. Clays and Clay Minerals (submitted).

Kilaas, R. (1998) Optical and near-optical filters in high-resolution electron microscopy. Journal of Microscopy, 190, 45-51.

Kim, J.-W., Peacor, D.R., Tessier, D. and Elsass, F. (1995) A technique for maintaining texture and permanent expansion of smectite interlayers for TEM observations. Clays and Clay Minerals, 43, 51-57.

Krekeler, M.P.S., Guggenheim, S. and Rakovan, J. (2004) A microtexture study of 
palygorskite-rich sediments from the Hawthorne Formation, southern Georgia, by transmission electron microscopy and atomic force microscopy. Clays and Clay Minerals, 52, 263-274.

Kogure, T. and Banfield, J. F. (2000) New insights into the biotite chloritization mechanism via polytype analysis. American Mineralogist, 85, 1202-1208.

Murakami, T., Sato, T. and Watanabe, T. (1993) Microstructure of interstratified illite/smectite at $123 \mathrm{~K}$ : A new method for HRTEM examination. American Mineralogist, 78, 465-468.

Richardson, S.M. and Richardson, J.W., Jr. (1982) Crystal structure of a pink muscovite from Archer's Post, Kenya: Implications for reverse pleochroism in dioctahedral micas. American Mineralogist, 67, 69-75.

Stixrude, L. and Peacor, D.R. (2002) First-principles study of illite-smectite and implications for clay mineral systems. Nature, 420, 165-168.

Stucki, J.W. and Tessier, D. (1991) Effects of iron oxidation state on the texture and structural order of Na-nontronite gels. Clays and Clay Minerals, 39, 137-143.

Tillick, D.A., Peacor, D.R. and Mauk, J.L. (2001) Genesis of dioctahedral phyllosilicates during hydrothermal alteration of volcanic rocks: I. The Golden Cross epithermal deposit, New Zealand. Clays and Clay Minerals,49, 126-140.

Vali, H. and Hesse, R. (1990) Alkylammonium ion treatment of clay minerals in ultrathin section: A new method for HRTEM examination of expandable layers. American Mineralogist, 75, 1443-1446.

Vali, H. and Köster, H.M. (1986) Expanding behaviour, structural disorder, regular and 
random irregular interstratification of 2:1 layer-silicates studied by high-resolution images of transmission electron microscopy. Clay Minerals, 21, 827-859.

Yan, Y., Tillick, D.A., Peacor, D.R. and Simmons, S.F. (2001) Genesis of dioctahedral phyllosilicates during hydrothermal alteration of volcanic rocks: II. The Broadlands-Ohaaki hydrothermal system, New Zealand. Clays and Clay Minerals,49, 141-155. 
Figure captions

Figure 1. Crystal structure of rectorite-like I-S with $\mathrm{d}_{001}=2.3 \mathrm{~nm}$ and corresponding simulated image normal to [530]. The basal-spacings of the illitic and smectitic layers of rectorite-like I-S were assumed to be 1.0 and $1.3 \mathrm{~nm}$ respectively. I and $\mathrm{S}$ stand for the illitic and smectitic layers, respectively. The defocus amount, specimen thickness, and objective aperture radius were $-42 \mathrm{~nm}$ (the Scherzer focus), $4 \mathrm{~nm}$, and $0.35 \mathrm{~nm}^{-1}$ for the simulation.

Figure 2. Simulated images of rectorite-like I-S with $\mathrm{d}_{001}=2.0$ (a), 2.3 (b), 3.0 (c) and $6.0 \mathrm{~nm}(\mathrm{~d})$ normal to [530]. The basal-spacings of the smectitic layer of rectorite-like I-S were 1.0, 1.3, 2.0 and $5.0 \mathrm{~nm}$, respectively. Arrows show examples of bright fringes appearing in the smectitic interlayers. Short, vertical bars indicate slightly dark fringes in the smectitic interlayers occurring due to the effect of truncation of a Fourier series. $\mathrm{T}$ and $\mathrm{O}$ stand for a tetrahedral and octahedral sheet, respectively. The defocus amount, specimen thickness, and objective aperture radius were $-42 \mathrm{~nm}, 4 \mathrm{~nm}$, and $3.5 \mathrm{~nm}^{-1}$ for the simulations.

Figure 3. Selected area electron diffraction patterns of rectorite (RAr-1, Arkansas) (a), sample 435 (b), 435 intercalated with $\mathrm{C}_{18}$-alkylammonium ions (c), 635 (d), 656 (e), and 756 (f). The arrows show 001 or 002 reflections; 1.00 (a), 1.28 (b), 1.35 (c), $1.14(\mathrm{~d}), 1.14(\mathrm{e})$, and $1.00 \mathrm{~nm}$ (f). Some of the reflections are diffuse or elongated, and the d values are calculated based on the head points of the arrows.

Figure 4. TEM images of sample 435 at low magnification (a) and at high 
magnifications (b and c). Each bracket shows one T-O-T silicate layer; I accompanied by a pair of bars indicates one illitic layer and $S$ with a pair of bars one smectitic layer. Each bar near I or S is located at the center of an octahedral cation layer plane. A question mark, ?, indicates an area with ambiguous lines. The distance between a pair of bars with I is $1.0 \mathrm{~nm}$.

Figure 5. TEM images of sample 635 at low magnification (a) and at high magnifications ( $b$ and $c$ ). The two pairs of two facing arrows in Figure $5 b$ indicate a pair of dark lines between two M1 units, and the arrow in Figure 5c a more expanded part of a smectitic interlayer. See the caption of Figure 4 for abbreviations and others.

Figure 6. TEM images of sample 656 at low magnification (a) and at high magnification (b). See the caption of Figure 4 for abbreviations and others.

Figure 7. TEM image of sample 656 showing an illitic to smectitic change at one surface side of a T-O-T silicate layer (arrows with a and c) and another at the interlayer (arrows with I and S). Arrow with a indicate termination of a T-O-T silicate layer, an arrow with b separation of an M1 unit from a packet of three M1 units, and an arrow with c formation of a smectitic interlayer between two M1 units. A dark line at a smectitic interlayer (arrow with $\mathrm{S}$ ) becomes a bright line at an illitic interlayer (arrow with I) with changing a spacing. See the caption of Figure 4 for abbreviations and others.

Figure 8. TEM image of sample 656 showing a possible layer-by-layer transformation. Arrows with a, b, c, and d show smectitic, illitic, smectitic, and illitic nature within 
one interlayer indicated by arrows with I and S. See the caption of Figure 4 for abbreviations and others.

Figure 9. TEM images of sample 756 at low magnification and at high magnification in inset. Arrows show M3 units. See the caption of Figure 4 for abbreviations and others.

Figure 10. TEM images of sample 756 showing changes in smectitic and illitic nature at the packet boundaries. (a) Packets 1, 2 and 3 at low magnification, (b) those at high magnification in area $\mathrm{b}$ in Figure 10a, (c) those at high magnification in area c, and (d) those at high magnification in area d. Numbers 1, 2 and 3 in Figure 10a correspond to packets 1, 2 and 3. Arrows with b, c and d in Figure 10a indicate the areas enlarged in Figure 10b, 10c and 10d, respectively. Arrows with numbers 1, 2 and 3 in Figure 10b, 10c and 10d show widths of packet 1, 2 and 3. Arrows with I and $\mathrm{S}$ indicate illitic and smectitic nature, respectively, at the packet boundaries. The contrast of packet 2 in Figure 10b is different from the simulated image in Figure 1; this occurs because the plane of packet 2 in Figure 10b is approximately normal to [010]. See the caption of Figure 4 for abbreviations and others. 


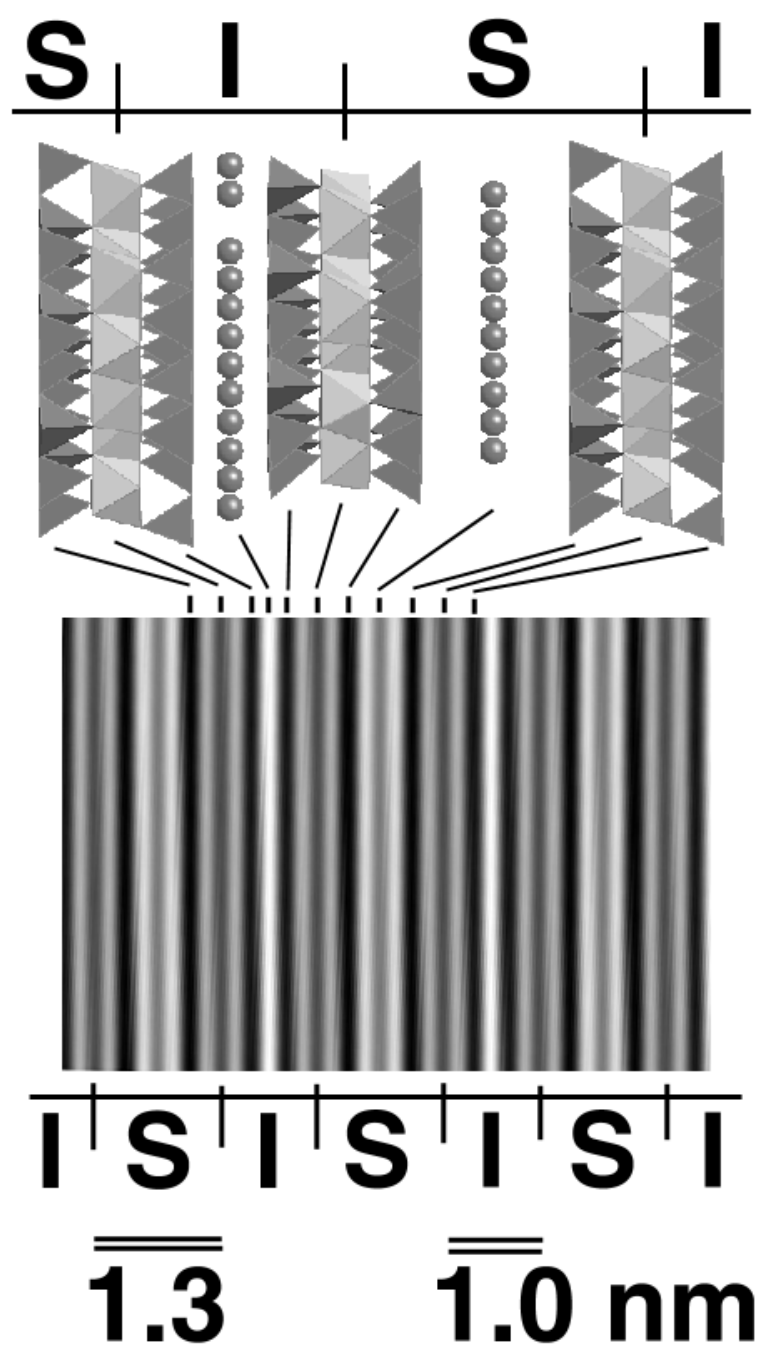

Figure 1 


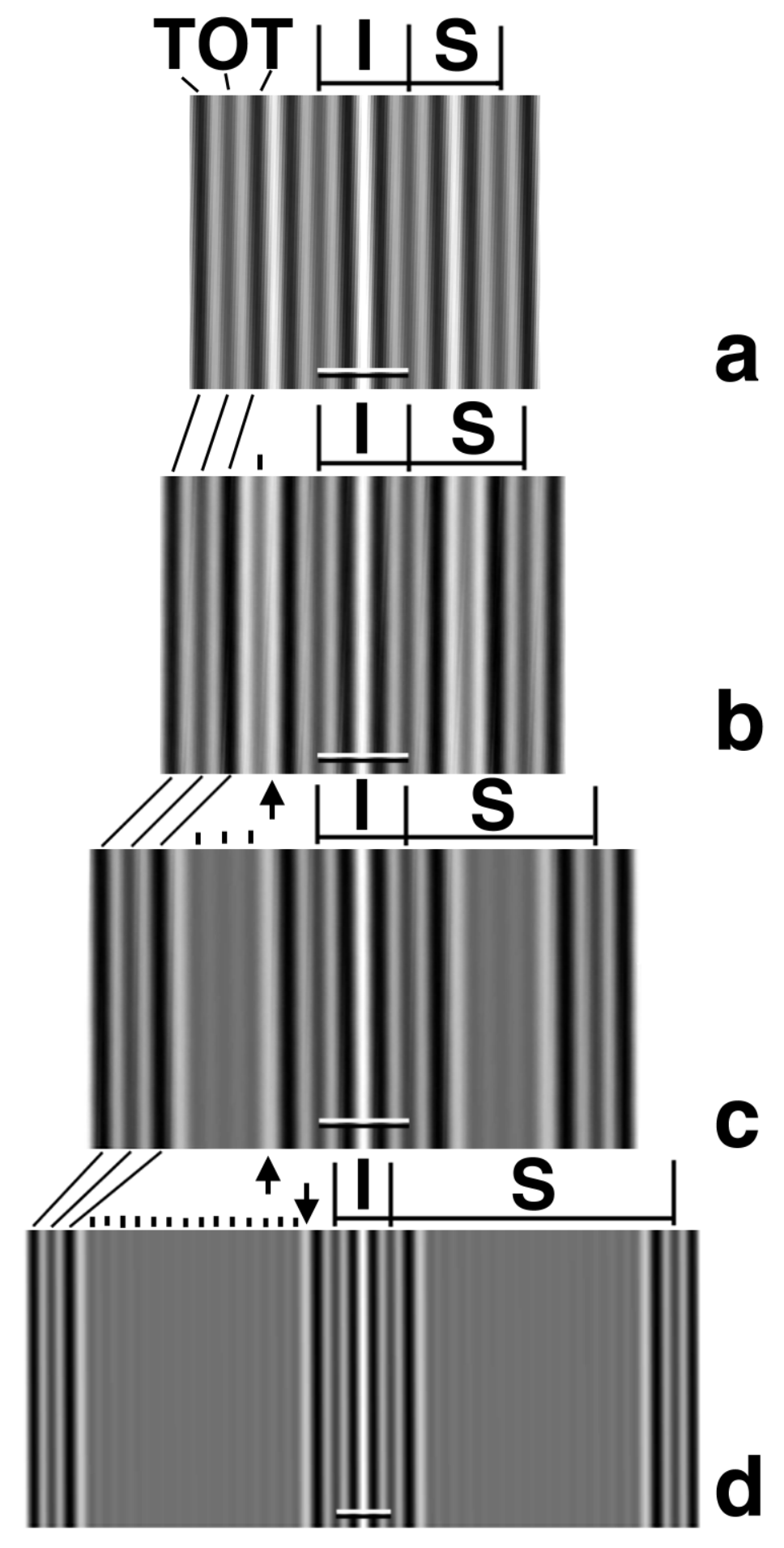

Figure 2 

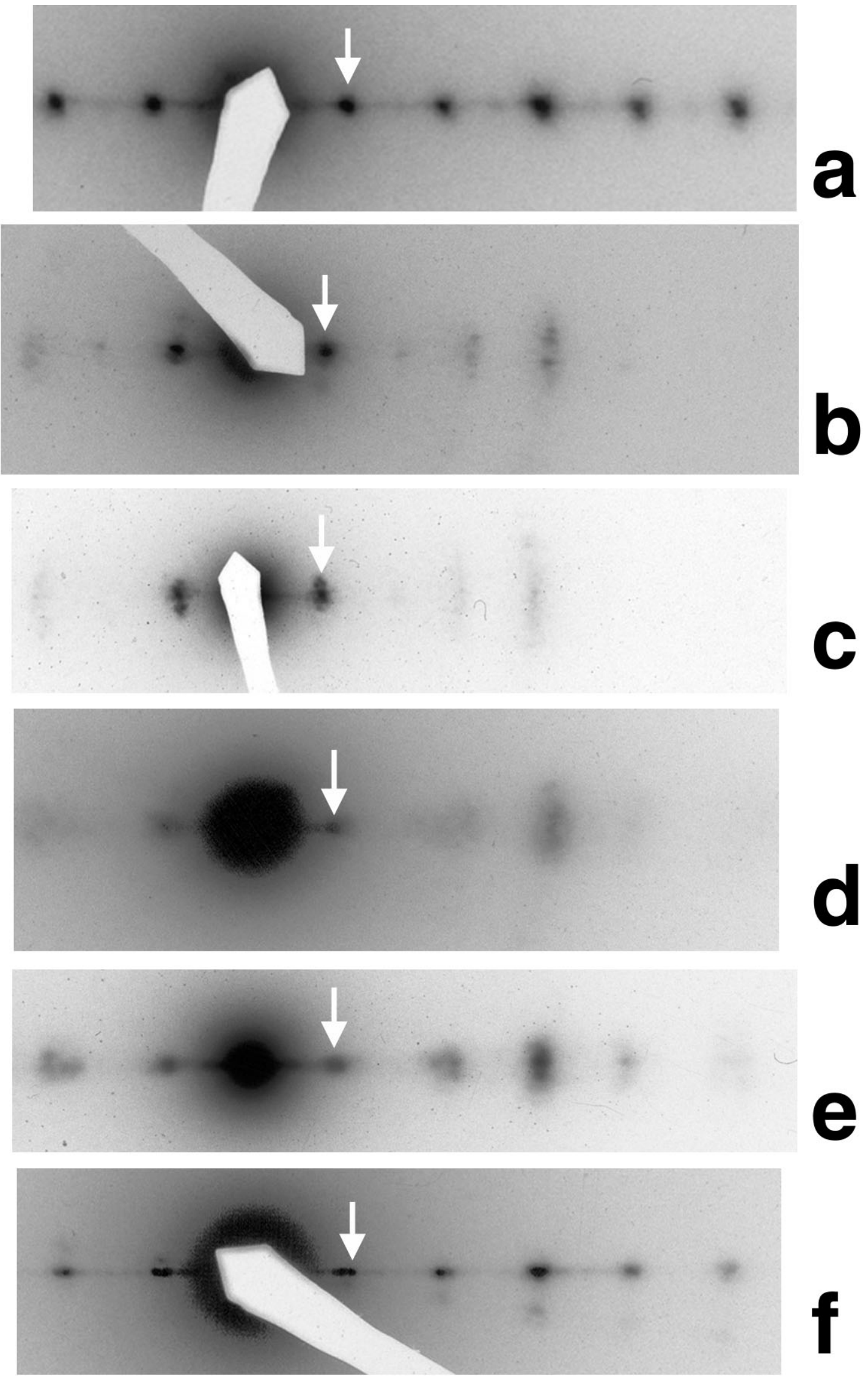

Figure 3 


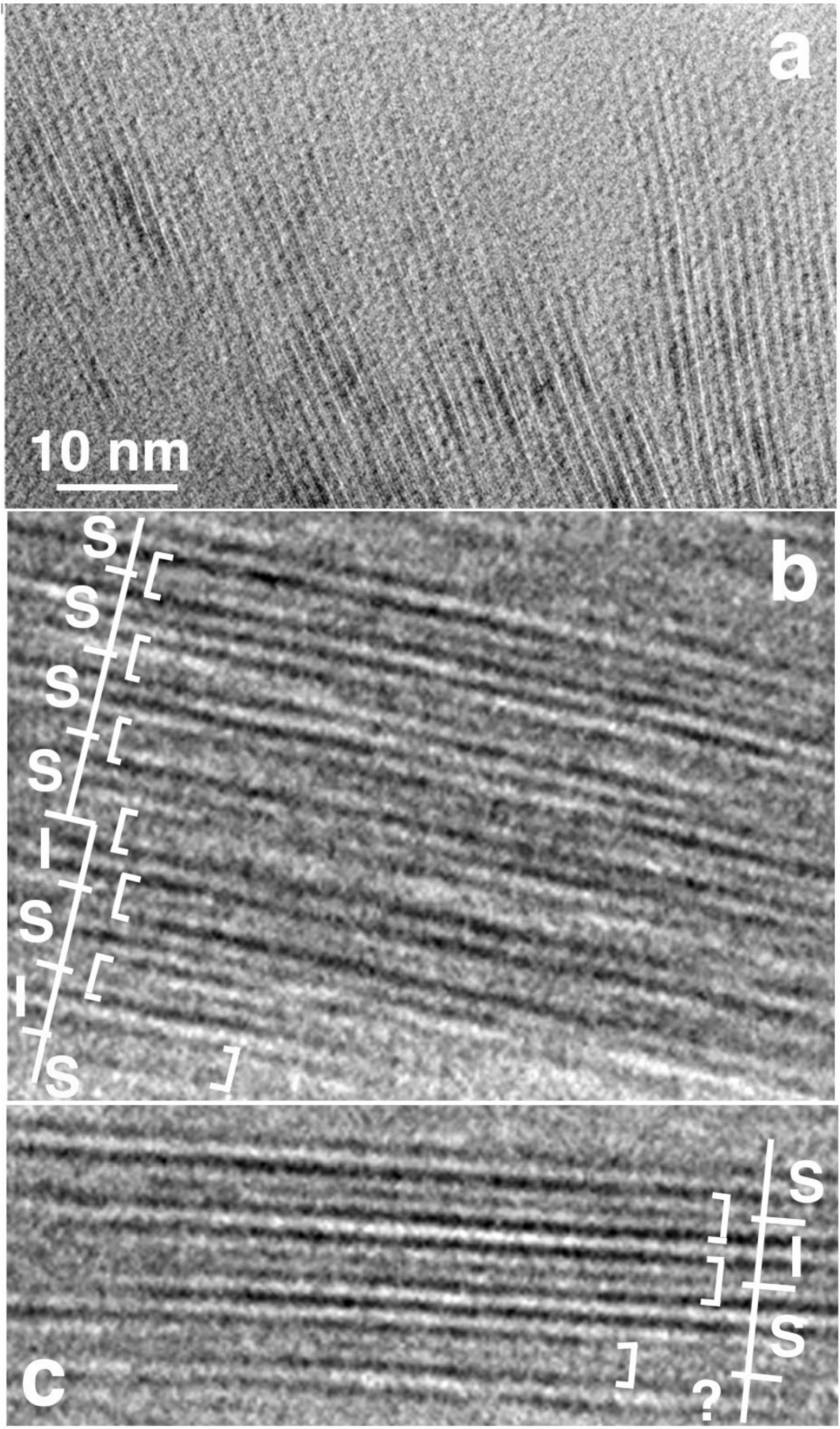




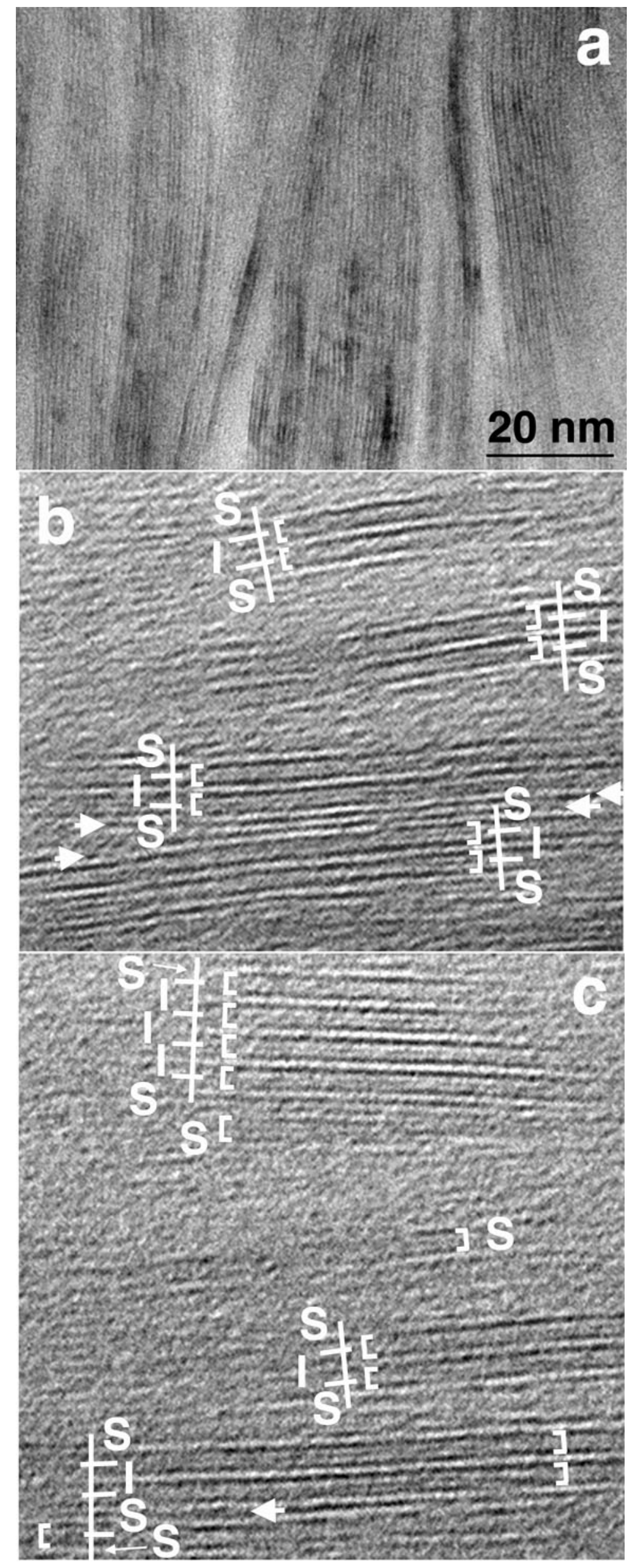

Figure 5 

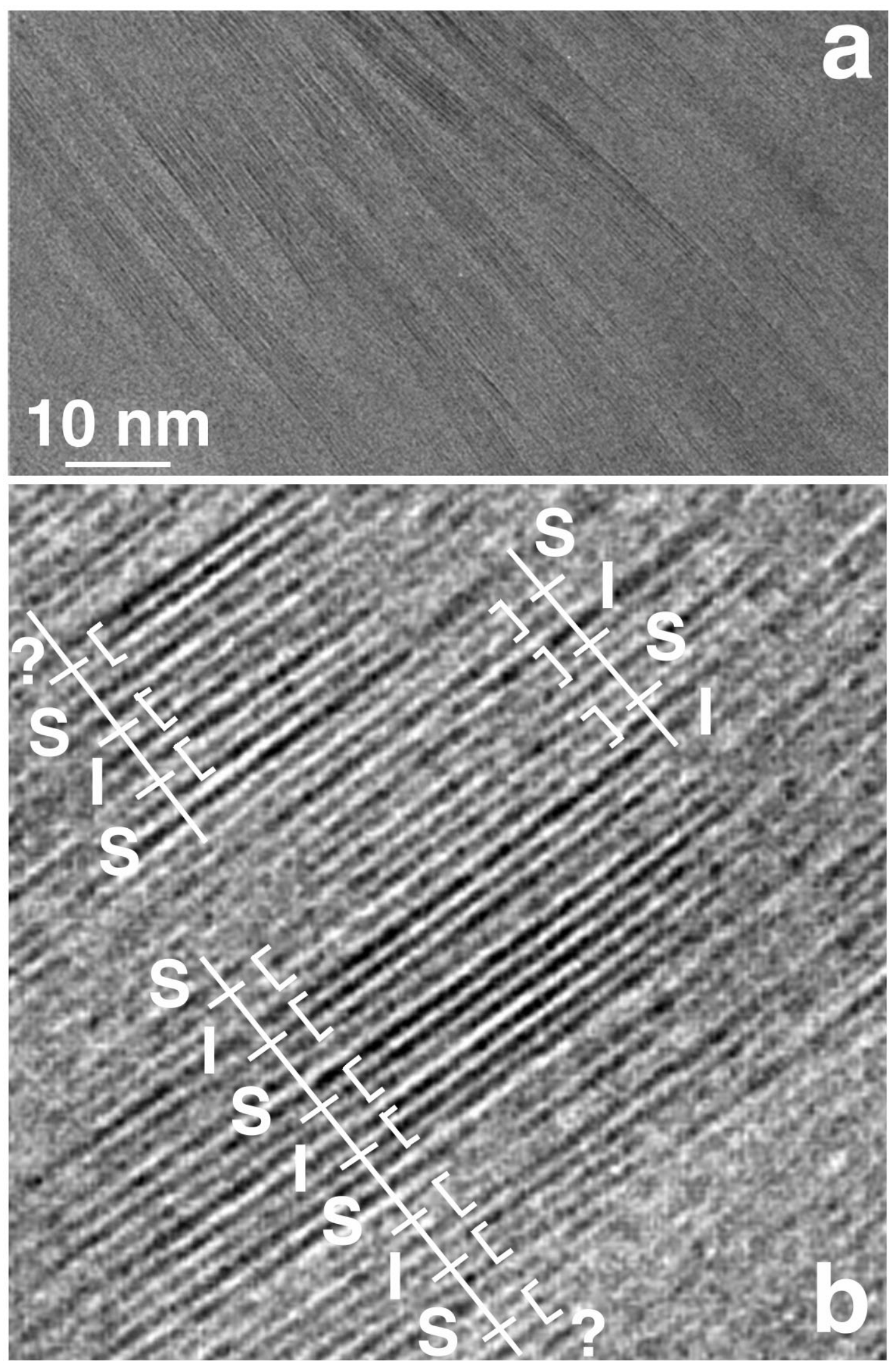

Figure 6 


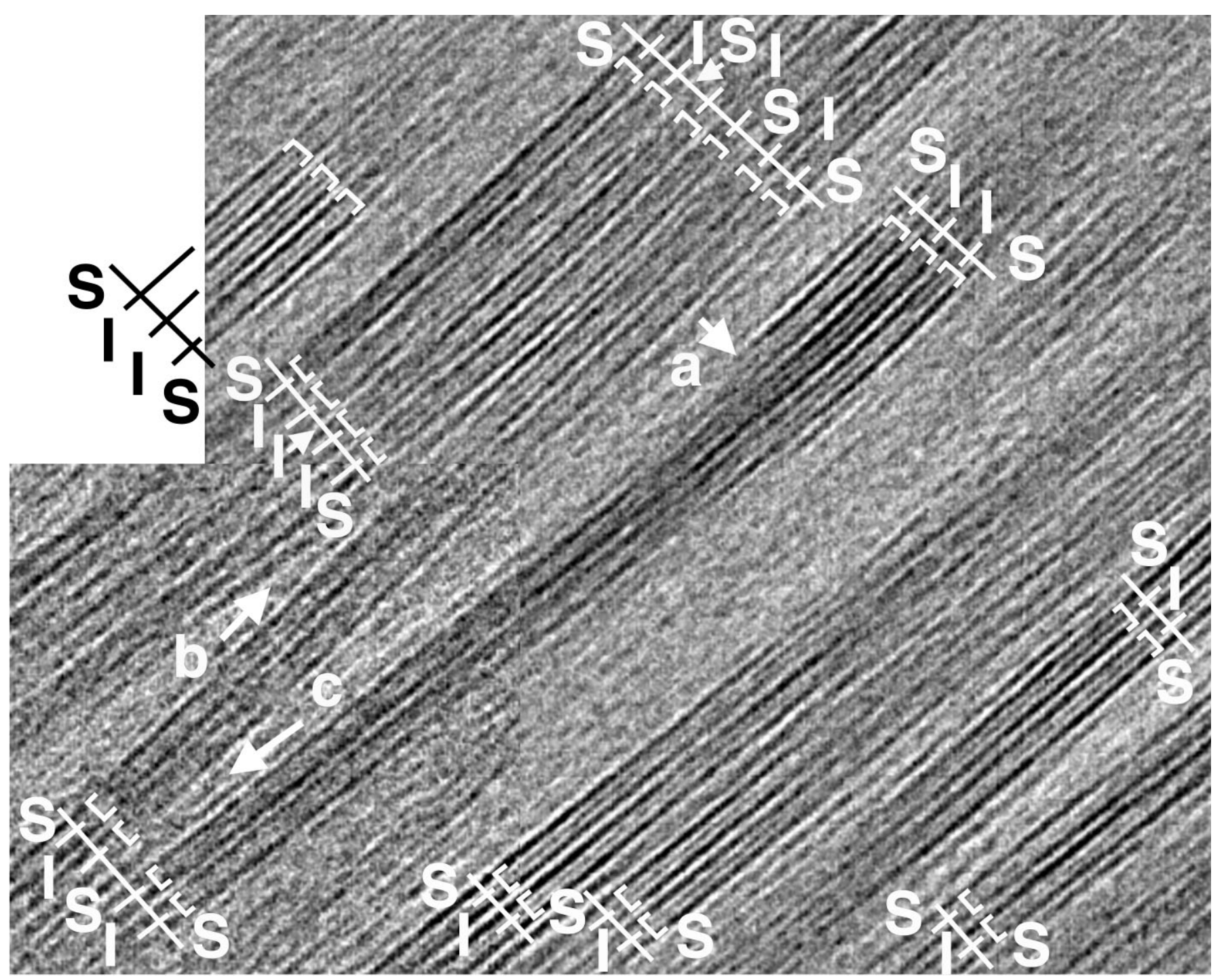

Figure 7 


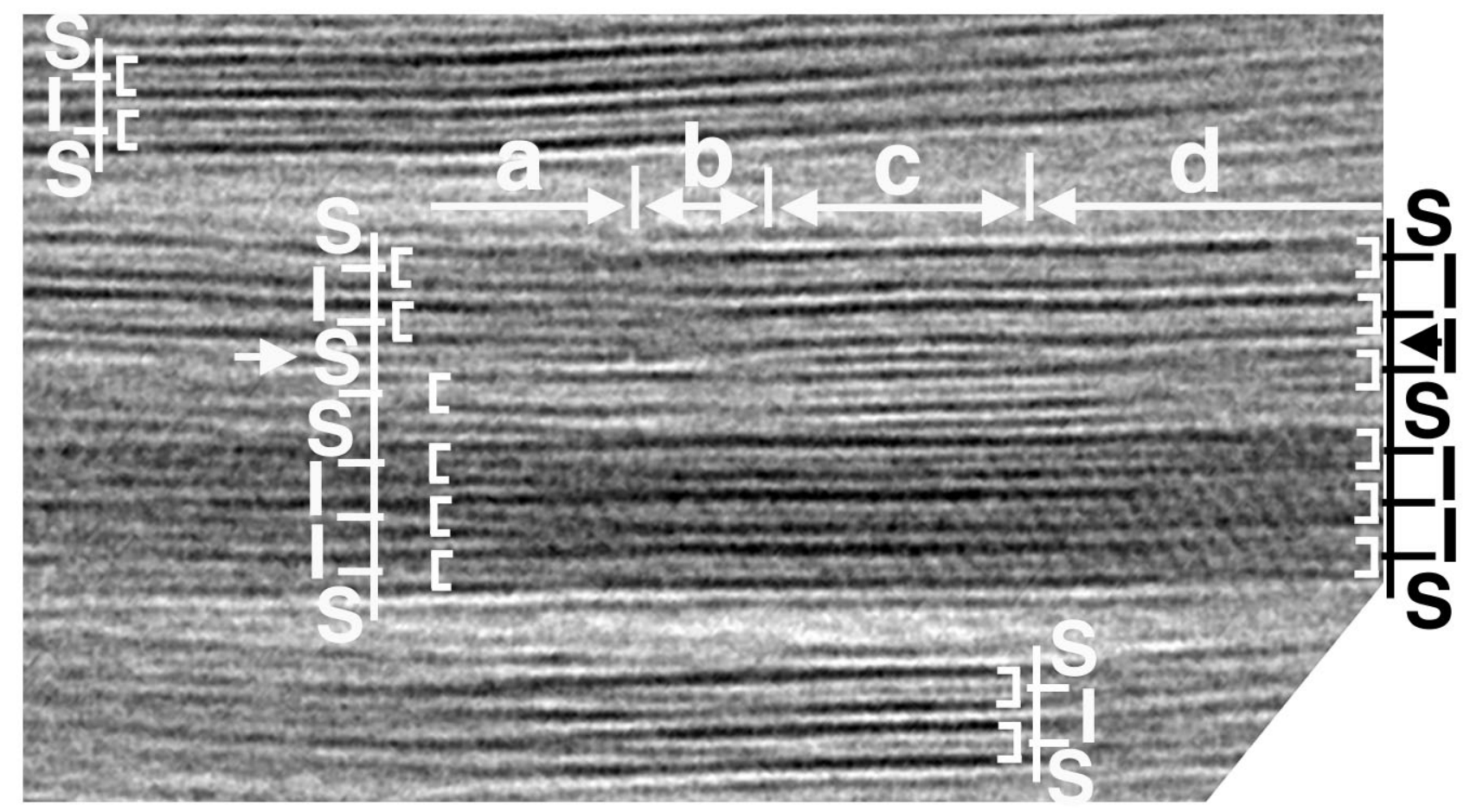




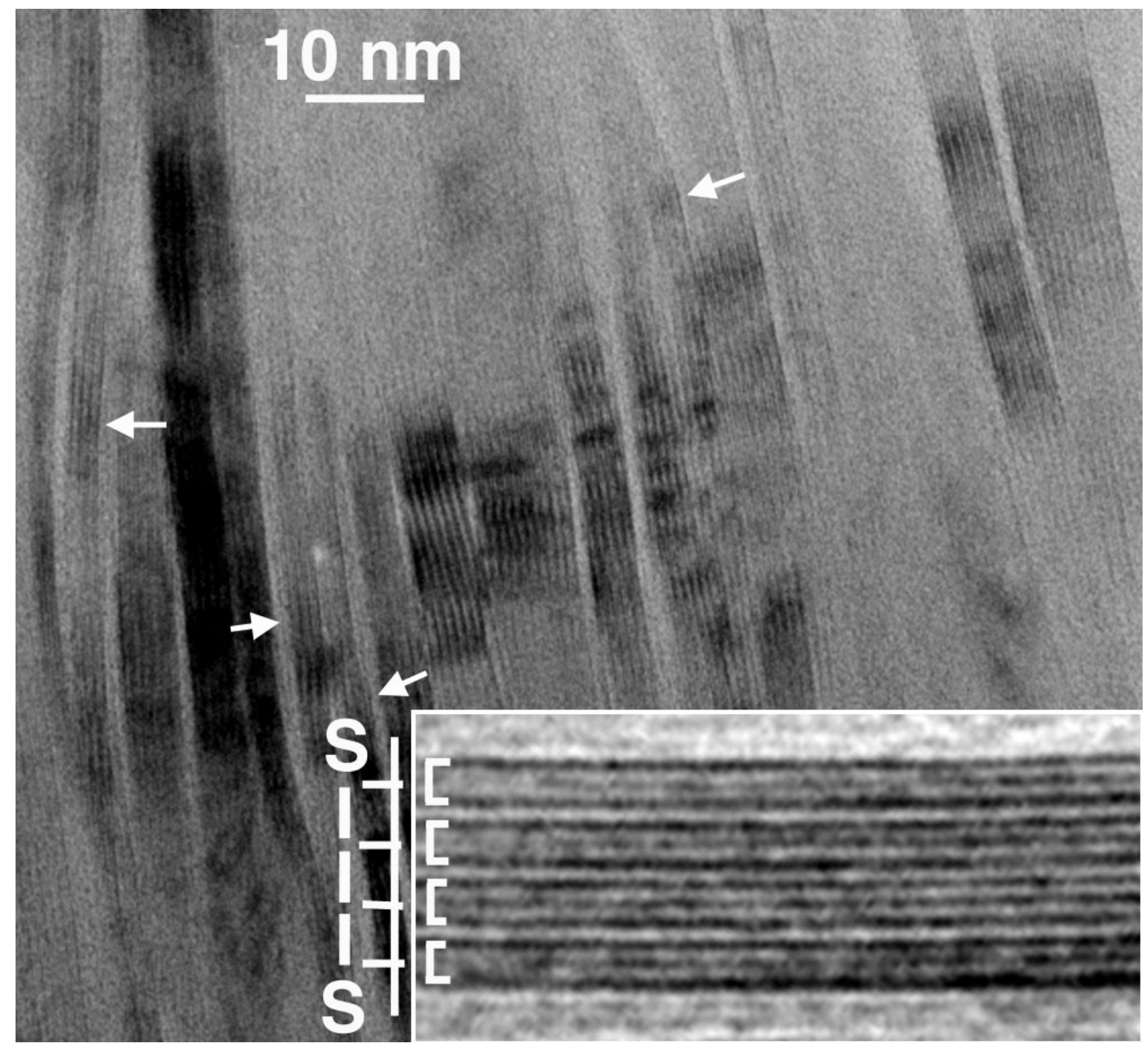

Figure 9 


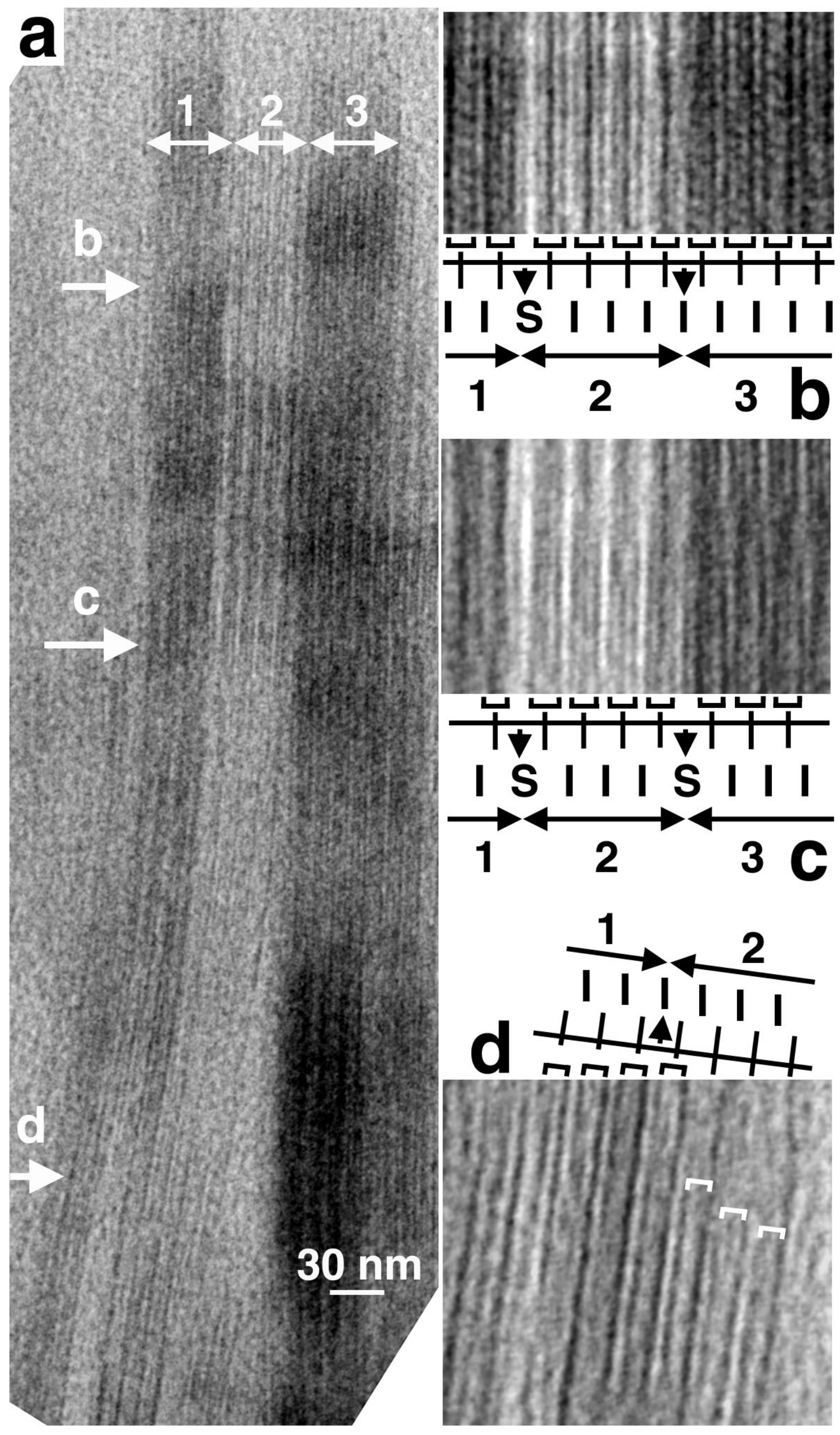

